\title{
Elevated fecal mitochondrial DNA from symptomatic norovirus infections suggests potential health relevance of human mitochondrial DNA in fecal source tracking
}

Kevin J. Zhu, Brittany Suttner, Jackie Knee, Drew Capone, Christine L. Moe, Christine E. Stauber, Kostas T. Konstantinidis, Thomas E. Wallach, Amy J. Pickering, Joe Brown

\section{Corresponding Author}

Joe Brown -Department of Environmental Sciences and Engineering, Gillings School of Global Public Health, University of North Carolina at Chapel Hill, Chapel Hill, North Carolina 27599, United States

\section{Author Information}

Kevin J. Zhu - School of Civil and Environmental Engineering, Georgia Institute of Technology, Atlanta, Georgia 30332, United States

Brittany Suttner - School of Civil and Environmental Engineering, Georgia Institute of Technology, Atlanta, Georgia 30332, United States

Jackie Knee -Department of Disease Control, London School of Hygiene and Tropical Medicine, London, United Kingdom

Drew Capone -Department of Environmental Sciences and Engineering, Gillings School of Global Public Health, University of North Carolina at Chapel Hill, Chapel Hill, North Carolina 27599, United States

Christine L. Moe - Center for Global Safe Water, Sanitation, and Hygiene, Rollins School of Public Health, Emory University, Atlanta, Georgia 30322, United States

Christine E. Stauber - Department of Population Health Sciences, School of Public Health, Georgia State University, Atlanta, Georgia 30302, United States

Kostas T. Konstantinidis - School of Civil and Environmental Engineering, Georgia Institute of Technology, Atlanta, GA 30332, United States

Thomas E. Wallach - Division of Pediatric Gastroenterology, SUNY Downstate Health

Amy J. Pickering - Department of Civil and Environmental Engineering, University of California, Berkeley, California 94720, United States 


\section{Abstract}

43 An end goal of fecal source tracking (FST) is to provide information on risk of transmission of

44 waterborne illnesses associated with fecal contamination. Ideally, concentrations of FST markers

45 in ambient waters would reflect exposure risk. Human mtDNA is an FST marker that is exclusively

46 human in origin and may be elevated in feces of individuals experiencing gastrointestinal

47 inflammation. In this study, we examined whether human mtDNA is elevated in fecal samples

48 from individuals with symptomatic norovirus infections using samples from the US, Mozambique,

49 and Bangladesh. We quantified hCYTB484 (human mtDNA) and HF183/BacR287 (human-

50 associated Bacteroides) FST markers using droplet digital PCR. We observed the greatest

51 difference in concentrations of hCYTB484 when comparing samples from individuals with

52 symptomatic norovirus infections versus individuals without norovirus infections or diarrhea

53 symptoms: 3,820\% increase in US samples $(p$-value $=0.062), 308 \%$ in Mozambique $(p$-value $=$

$540.061)$, and $648 \%$ in Bangladesh $(p$-value $=0.035)$. We did not observe any trends in

55 concentrations of HF183/BacR287 in the same samples. These results suggest concentrations of

56 fecal mtDNA increase during symptomatic norovirus infection and that mtDNA in environmental

57 samples may represent an unambiguously human source-tracking marker that correlates with

58 enteric pathogen exposure risk. 


\section{Introduction}

60 Fecal source tracking (FST) aims to detect fecal contamination in environmental samples and

61 identify the source using a variety of chemical and biological methods. Method validation studies

62 to date have demonstrated FST markers targeting human-associated microbial DNA to have

63 variable sensitivity (true positive rate) and specificity (true negative rate) across geographies ${ }^{1-5}$.

64 Human mitochondrial DNA (mtDNA) markers, having been demonstrated to have high sensitivity

$65{ }^{6-9}$ and high specificity ${ }^{6-9}$ across varying geographies, may complement the use of microbial FST

66 targets, especially in settings or environmental matrices where other FST markers have not been

67 previously validated ${ }^{9}$.

69 In addition to retaining high sensitivity and specificity, an ideal FST marker should also convey

70 information about the risk associated with detected fecal contamination: increasing concentration

71 of FST markers in environmental samples should indicate increasing risk of gastrointestinal and

72 other waterborne illnesses associated with exposure ${ }^{10}$. However, such a marker has not yet been

73 identified. mtDNA FST markers differ from microbial markers because they target host DNA

74 instead of host-associated microbial DNA. The main cellular sources of fecal mtDNA are thought

75 to be intestinal epithelial cells (IEC) ${ }^{6,7}$ and white blood cells (leukocytes) ${ }^{6,11}$. IECs constitute the

76 intestinal epithelium that prevents the entry of harmful substances into the body while selectively

77 allowing entry of beneficial nutrients. Leukocytes transmigrate into the intestinal lumen during

78 enteric infections. Because of these origins, fecal mtDNA concentrations may exhibit baseline

79 levels during homeostasis (e.g., IEC shedding to balance IEC proliferation) with elevated levels

80 during inflammatory events (e.g., infection triggering leukocyte transmigration, increased

81 apoptosis, IEC extrusion and shedding) ${ }^{12,13}$. 
83 A key assumption often used when assessing risk associated with fecal indicators is that

84 concentrations of fecal indicators covary with concentrations of sewage present and, therefore,

85 concentrations of pathogens. If concentrations of mtDNA FST markers increase during cases of

86 enteric infections, specifically in symptomatic cases where vomiting and/or diarrhea facilitates the

87 shedding of pathogens, mtDNA markers may advance the capabilities of FST markers by

88 providing risk information beyond the assumed covariance between concentrations of indicator

89 and pathogen. Associations between mtDNA FST markers and enteric infections have not yet been

90 studied, and it is unknown whether concentrations of fecal mtDNA are indicative of symptomatic

91 enteric infections.

92

93 The aim of this study was to investigate whether concentrations of a human mtDNA FST marker

94 are higher in feces from individuals with symptomatic norovirus infections than feces from

95 individuals without. We used archived fecal samples from participants in studies conducted in the

96 US, Mozambique, and Bangladesh, and compared fecal mtDNA concentrations across three

97 groups: (1) no detected enteric infection and no diarrhea, (2) norovirus infection and no diarrhea,

98 and (3) norovirus infection and diarrhea. We hypothesized that concentrations of fecal mtDNA

99 will be highest in feces from symptomatic norovirus infections versus those from individuals with 100 asymptomatic norovirus infections or no enteric infections.

101

102 Materials and Methods

103 Feces Samples. We obtained human fecal samples from three different studies conducted in the

104 US, Mozambique, and Bangladesh. We first investigated the US samples, using pairs of one pre- 
and one post-challenge sample per subject from a norovirus Genogroup I (GI) challenge study in

106 which norovirus-spiked oysters were used as the intentional exposure ${ }^{14}$. These pre- and post-

107 challenge pairs were from six subjects who developed asymptomatic norovirus infections and five

108 subjects who developed symptomatic norovirus infections (Table 1). In the challenge study,

109 symptoms (chills, cramping, diarrhea, fatigue, fever, headache, myalgia, nausea, vomiting, white

110 blood cell shift) were recorded during the challenge period and follow-up visits ${ }^{14}$. To be classified

111 as symptomatic, a subject had to have at least one of the above symptoms, with fever requiring at

112 least one other associated symptom.

114 Following initial results from the US samples (Figure S1), we expanded the analysis to include

115 archived fecal samples from two other studies: 1) a cross-sectional study of child (under four years

116 of age) enteric infections in urban Maputo, Mozambique ${ }^{15,16}$ and 2) an experimental trial

117 evaluating the effect of passive chlorination devices at shared water points on child (under five

118 years of age) diarrhea prevalence in urban Bangladesh ${ }^{17,18}$. We classified the fecal samples using

119 the following criteria: 1) no enteric pathogens detected and from individuals with no reported

120 diarrhea (hereafter referred to as enteric ${ }^{-}$asymptomatic), 2) norovirus GI/GII detected and from

121 individuals with no reported diarrhea (noro ${ }^{+}$asymptomatic), 3) norovirus GI/GII detected, and from

122 individuals with reported diarrhea (noro ${ }^{+}$symptomatic). Detection of enteric pathogens in the 123 archived Mozambique and Bangladesh samples was determined by the Luminex (Austin, Texas,

124 US) xTAG® Gastrointestinal Pathogen Panel RUO (GPP) in previous studies ${ }^{15,18}$. The GPP

125 detects the nucleic acid markers of 15 bacterial, viral, and parasitic enteric pathogens, including

126 norovirus GI/GII with a limit of detection for norovirus GI/GII on the order of $10^{6}$ genome

127 copies/gram of feces ${ }^{19}$. There were low numbers of norovirus-positive feces in the Mozambique 
and Bangladesh samples, and feces positive for norovirus were often positive for another GPP

$\operatorname{target}^{15,18}$. Because of this, we included norovirus-positive feces that were positive for additional

130 pathogen(s) in the noro ${ }^{+}$asymptomatic and noro ${ }^{+}$symptomatic groups. We identified

131 enteric $^{-}$asymptomatic samples by selecting feces that were negative for all Luminex GPP targets.

132 Reported diarrhea in the Bangladesh and Mozambique studies was based on caregiver-reported

133 diarrhea criteria of $\geq 3$ loose or watery feces in a 24 -hr period with a 1 -week recall period. Because

134 the Bangladesh ${ }^{17}$ and Mozambique ${ }^{15}$ studies observed low prevalence of caregiver-reported

135 diarrhea, we were limited in the number of noro ${ }^{+}$symptomatic samples we could examine (Table

$1361)$.

138 DNA Extraction and ddPCR. Prior to DNA extraction, we stored fecal samples at $-80^{\circ} \mathrm{C}$. For US

139 samples, we performed DNA extractions using $0.1 \mathrm{~g}$ of fecal sample and the MO BIO PowerSoil@

140 kit (Carlsbad, CA, USA) following manufacturer's instructions. For Mozambique and Bangladesh

141 samples, we performed DNA extractions using $0.1 \mathrm{~g}$ of fecal sample and the Qiagen QIAamp®

14296 PowerFecal QIAcube ${ }^{\circledR}$ HT Kit automated on the Qiagen QIAcube $®$ HT platform (Hilden,

143 Germany) following manufacturer's instructions, using soil grinding SK38 bead tubes (Bertin

144 Corp., Rockville, MD, USA) containing $650 \mu 1$ pre-warmed Buffer PW1 and homogenizing the

145 bead tubes on a vortexer for 10 minutes. Following DNA extraction, we stored all extracts at -

$14680^{\circ} \mathrm{C}$ until analysis. We quantified hCYTB $484{ }^{9}$ and HF183/BacR287 ${ }^{20}$ markers through droplet

147 digital PCR (ddPCR) on Bio-Rad QX200"TM Droplet Digital ${ }^{\mathrm{TM}}$ PCR (Hercules, CA, USA) using 148 methods developed previously ${ }^{9}$ and normalized marker concentrations to nanograms of double 149 stranded DNA (ng dsDNA) to account for differences in moisture content between feces and any 150 potential differential recovery between kits ${ }^{21}$. Results of biological replicates for a subset of 
151 samples are in supporting information (Table S1). Minimum Information for Publication of

152 Quantitative Digital PCR Experiments ${ }^{22}$ is included in the supporting information (Table S2).

154 Data Analysis. Because the US samples were collected longitudinally from each subject, we 155 applied the Wilcoxon signed rank paired test to the pre- and post-challenge US samples. For the 156 Mozambique and Bangladesh sample sets (cross-sectional data), we used the Kruskal-Wallis test, 157 followed with the Dunn test with Benjamini-Hochberg adjustment. We calculated effect sizes for $158 \log _{10}$ transformed concentrations through a difference in means approach using Cohen's $d$, the 159 difference between the two means divided by the pooled standard deviation. To compare the

160 relative influences of potential confounders, we fitted a generalized linear model (GLM) using a

161 Gaussian identity function to the Mozambique and Bangladesh sample sets using reported diarrhea 162 and norovirus GI/GII detected/not detected (as determined by the GPP) as the independent 163 variables and $\log _{10}$ values of hCYTB484 normalized to ng of dsDNA as the dependent variable 164 while adjusting for number of pathogens detected (as determined by the GPP), sex, age 165 (continuous, number of months), and country (Mozambique or Bangladesh). More information on 166 model fitting can be found in the supporting information. We performed data analyses in $\mathrm{R}$ version $167 \quad 4.0 .1$

169 Results and Discussion

170 We observed the largest differences in median hCYTB484 copies / ng dsDNA between the 171 enteric ${ }^{-}$asymptomatic and noro ${ }^{+}$symptomatic groups (Figure 1, Table 2): 3,820\% increase for US 172 samples, 308\% increase for Mozambique samples, and 648\% increase for Bangladesh samples. 173 The larger effect sizes between enteric ${ }^{-}$asymptomatic and noro ${ }^{+}$symptomatic versus 
174 enteric $^{-}$asymptomatic and noro ${ }^{+}$asymptomatic across all three countries (Table 2) suggest that

175 fecal mtDNA concentrations are higher in symptomatic norovirus infections than in asymptomatic

176 norovirus infections (effect sizes calculated as the difference between means normalized to the

177 pooled standard deviation). To investigate what variables influenced fecal mtDNA concentrations,

178 we standardized the GLM regression coefficients to account for different units of measurements

179 and variances of each variable. The standardized GLM regression coefficients (Table S3) show

180 reported diarrhea $(0.16,95 \% \mathrm{CI}: 0-0.32, p$-value $=0.045)$, norovirus detected $(0.12,95 \%$ CI: -

$1810.16-0.39, p$-value $=0.38)$, age in months $(-0.12,95 \% \mathrm{CI}:-0.28-0.03, p$-value $=0.12)$, and

182 country (Bangladesh or Mozambique) $(0.19,95 \% \mathrm{CI}:-0.36--0.03, p$-value $=0.018)$ as having

183 the largest magnitudes. However, only reported diarrhea and country had $p$-values $<0.05(0.045$

184 and 0.018, respectively). Comparison of the standardized regression coefficients after adjusting

185 for other potential biological confounders suggest that, of the variables tested, diarrhea and country

186 had the largest influences on fecal mtDNA concentrations.

188 The largest increase in concentrations of fecal mtDNA occurred in the US samples, for several 189 possible reasons. Firstly, epithelial cell proliferation declines with age ${ }^{23}$. Compared to the adults

190 in the US study, the children in the Mozambique and Bangladesh studies may have had higher

191 levels of proliferation even when not experiencing diarrhea. Secondly, fecal mtDNA

192 concentrations may have varied due to environmental enteric dysfunction (EED) ${ }^{24}$. The

193 Mozambique and Bangladesh study settings had high prevalence of enteric pathogen exposure ${ }^{15,18}$

194 as measured by frequency of pathogen detection in feces ${ }^{25}$ : estimated $86 \%$ and $88 \%$ of feces

195 containing one or more pathogens in Mozambique and Bangladesh samples, respectively. EED, a

196 condition caused by persistent exposure to enteric pathogens, infections, or perturbations and 
197 characterized by deleterious changes in the intestinal epithelium, can result in malabsorption and

198 diminished growth and development in children. Despite deleterious changes associated with EED

199 that may potentially change fecal mtDNA concentrations, such as reduced intestinal villi, EED

200 typically presents with few or no acute symptoms, potentially reducing in the effect size we

201 observed in samples from Mozambique and Bangladesh. Lastly, the method of reporting diarrhea

202 differed between the US versus Mozambique and Bangladesh samples: clinical monitoring versus

203 caregiver reported. Caregiver-reported diarrhea is subject to recall biases ${ }^{26,27}$, which may have

204 resulted in misclassification of samples.

We did not observe any increases in HF183/BacR287 marker copies / ng dsDNA between the

207 enteric $^{-}$asymptomatic and noro ${ }^{+}$symptomatic groups (Figure 1), indicating that the elevated 208 mtDNA concentrations may be specific to mtDNA and not due to a bulk increase in fecal markers.

209 Furthermore, we detected the HF183/BacR287 marker in 52\% of samples, with only $31 \%$ of 210 samples above the lower limit of quantification (quantifiable), a finding consistent with 211 assessments of HF183 in individual human feces across the globe ${ }^{5,28}$. In contrast, $100 \%$ of samples

212 in this study were quantifiable for hCYTB484.

214 A variety of sources and processes related to the health of the gastrointestinal system influence

215 fecal mtDNA concentrations. Because the integrity of the intestinal epithelium is essential to the

216 host's health, IECs proliferate and are removed in a highly active and balanced cycle ${ }^{29}$. IEC

217 removal likely depends on the epithelium and host's health, including various potential

218 mechanisms: engulfment following apoptosis ${ }^{30,31}$, shedding into the intestinal lumen ${ }^{32-35}$,

219 shedding in response to pathogen or pathogen-associated insults ${ }^{36-38}$, and shedding during other 
220 pathological states such as inflammatory bowel disease, neoplastic growth ${ }^{39}$, and wound healing

$221{ }^{34}$. Additionally, current evidence of norovirus infection in humans points towards enterocytes in

222 the small intestines as the primary tropism ${ }^{40,41}$. Noroviruses, as non-enveloped viruses, are

223 presumed to have lytic effects on their host cells ${ }^{42}$, potentially releasing host mtDNA into the

224 intestinal lumen. Leukocytes can be found in feces from individuals with inflammatory diarrhea

$22540,43,44$, and neutrophils are highly abundant first responders, transmigrating across the intestinal

226 epithelium during enteric infections ${ }^{45}$. Lastly, there is emerging evidence of mtDNA's immune-

227 signaling role in inflammatory diseases: pathogen-associated signal ${ }^{46}$ and damage-associated

228 molecular pattern ${ }^{13,47}$. Many of these processes through which mtDNA is shed in feces are

229 involved with gastrointestinal health, lending plausibility to our observation of increased fecal

230 mtDNA during symptomatic norovirus infections. However, non-pathogenic diseases such as

231 inflammatory bowel disease and neoplastic growth may also cause elevated fecal mtDNA.

233 Several limitations qualify our results. Prevalences of reported diarrhea in the Bangladesh ${ }^{17}$ and

234 Mozambique ${ }^{15}$ trials were low, limiting the number of samples in our analysis and constraining

235 statistical power. Reported diarrhea in these studies was assessed through a caregiver survey and

236 is subject to observational and recall biases ${ }^{26,27}$. Multiple pathogens were commonly detected in

237 the Bangladesh and Mozambique fecal samples, with norovirus rarely detected alone. Co-

238 infections may have affected fecal mtDNA concentrations as well as symptomology; norovirus

239 may not have always been the cause of symptoms. While norovirus is an important cause of

240 gastroenteritis globally, there are other enteric pathogens that can be transmitted through exposure

241 to fecal contamination in the environment and are relevant to FST. 
243 A human-specific FST marker that is informative of risk of illness is needed because fecal indicator

244 bacteria exhibit non-specificity in the environment (cross-reactivity and regrowth) and because

245 human fecal contamination represents an important risk to human health ${ }^{48-52}$. In this study, we

246 observed increased concentrations of mtDNA in feces from individuals with symptomatic

247 norovirus infections when compared to feces from individuals without norovirus infections or

248 diarrhea symptoms. This suggests that mtDNA markers may serve as biomarkers of intestinal

249 inflammation and may provide risk-relevant information by increasing in concentration when an

250 individual is at higher risk of transmitting norovirus infection ${ }^{53}$. However, we need better

251 understanding of the cellular sources of fecal mtDNA, intactness of fecal mtDNA after defecation,

252 and what conditions modulate fecal mtDNA concentrations. Approaches investigating processes

253 relevant to gastrointestinal health (e.g., expression of IEC proliferation genes) could also help

254 identify relevant mechanisms that modulate fecal mtDNA. Studies on the fate and persistence of

255 fecal mtDNA ${ }^{8,54}$ are also needed to understand how the signal is attenuated in environments

256 relative to that of pathogens ${ }^{55}$. Because human mtDNA FST markers are typically found at lower

257 concentrations in sewage than those of other human-associated FST markers, improved

258 concentration and recovery methods of mtDNA are needed ${ }^{10}$. Despite these knowledge and

259 technical gaps, results from this study add to previous evidence supporting the utility human

260 mtDNA as FST markers. 
262 Table 1. Sample frame for this study.

\begin{tabular}{|c|c|c|c|c|c|}
\hline Country & $\begin{array}{c}\text { Individuals } \\
\text { from } \\
\text { which } \\
\text { samples } \\
\text { were } \\
\text { collected }\end{array}$ & $\begin{array}{c}\text { Ages of } \\
\text { individuals }\end{array}$ & enteric ${ }^{-}$asymptomatic & noro'asymptomatic & noro'symptomatic $^{+}$ \\
\hline US a & 11 & $\begin{array}{c}\text { Adult } \\
(18 \text { to } 50 \\
\text { years of } \\
\text { age })\end{array}$ & 11 & 6 & 5 \\
\hline Mozambique & 66 & $\begin{array}{c}\text { Children } \\
(<4 \text { years } \\
\text { of age })\end{array}$ & 26 & 29 & 11 \\
\hline Bangladesh & 120 & $\begin{array}{c}\text { Children } \\
(<5 \text { years } \\
\text { of age })\end{array}$ & 49 & 68 & 3 \\
\hline
\end{tabular}

a All US samples were part of paired samples (pre-challenge and post-challenge) from 11 individuals. 6 individuals did not develop symptoms; 5 individuals did develop symptoms.

Table 2. Comparison of median human mtDNA copies normalized to ng of dsDNA amongst the different health status groups.

\begin{tabular}{|c|c|c|c|c|c|c|c|c|c|c|}
\hline \multirow[b]{2}{*}{ Sample Set } & \multirow{2}{*}{$\begin{array}{c}\text { Kruskal- } \\
\text { Wallis } \\
\text { test }\end{array}$} & \multicolumn{3}{|c|}{$\begin{array}{c}\text { enteric }{ }^{-} \text {asymptomatic } \\
\text { versus noro }{ }^{+} \text {asymptomatic }\end{array}$} & \multicolumn{3}{|c|}{$\begin{array}{c}\text { noro }^{+} \text {asymptomatic versus } \\
\text { noro }^{+} \text {symptomatic }\end{array}$} & \multicolumn{3}{|c|}{$\begin{array}{c}\text { enteric }{ }^{-} \text {asymptomatic versus } \\
\text { noro }{ }^{+} \text {symptomatic }\end{array}$} \\
\hline & & $\begin{array}{l}\text { \% increase } \\
\text { in median } \\
\text { hCYTB484 } \\
\text { copies / ng } \\
\text { dsDNA }\end{array}$ & $\begin{array}{c}p- \\
\text { value }\end{array}$ & $\begin{array}{l}\text { effect } \\
\text { size }^{c}\end{array}$ & $\begin{array}{l}\% \text { increase } \\
\text { in median } \\
\text { hCYTB484 } \\
\text { copies / ng } \\
\text { dsDNA }\end{array}$ & $\begin{array}{c}p- \\
\text { value }\end{array}$ & $\begin{array}{l}\text { effect } \\
\text { size }^{c}\end{array}$ & $\begin{array}{l}\text { \% increase } \\
\text { in median } \\
\text { hCYTB484 } \\
\text { copies / ng } \\
\text { dsDNA }\end{array}$ & $\begin{array}{c}p- \\
\text { value }\end{array}$ & $\begin{array}{l}\text { effect } \\
\text { size }^{c}\end{array}$ \\
\hline US & N/A & $168 \%$ & $1^{b}$ & 0.60 & & & & $3,820 \%$ & $\begin{array}{c}0.062 \\
\mathrm{~b}\end{array}$ & 4.3 \\
\hline Mozambique & 0.068 & $138 \%$ & $0.36^{\mathrm{a}}$ & 0.32 & $223 \%$ & $0.15^{\mathrm{a}}$ & 0.39 & $308 \%$ & $\underset{\mathrm{a}}{0.061}$ & 0.70 \\
\hline Bangladesh & 0.024 & $111 \%$ & $0.14^{\mathrm{a}}$ & 0.27 & $585 \%$ & $\underset{\mathrm{a}}{0.057}$ & 1.2 & $648 \%$ & $\begin{array}{c}0.035 \\
\mathrm{a}\end{array}$ & 1.5 \\
\hline
\end{tabular}

${ }^{a}$ Dunn test adjusted with the Benjamini-Hochberg method for multiple comparisons

${ }^{\mathrm{c}}$ Effect size reported as the difference between the two sample means divided by the pooled standard deviation of the $\log _{10}$ transformed data (Cohen's $d$ ). The larger the effect size, the larger the difference between the mean of the two sample distributions. 

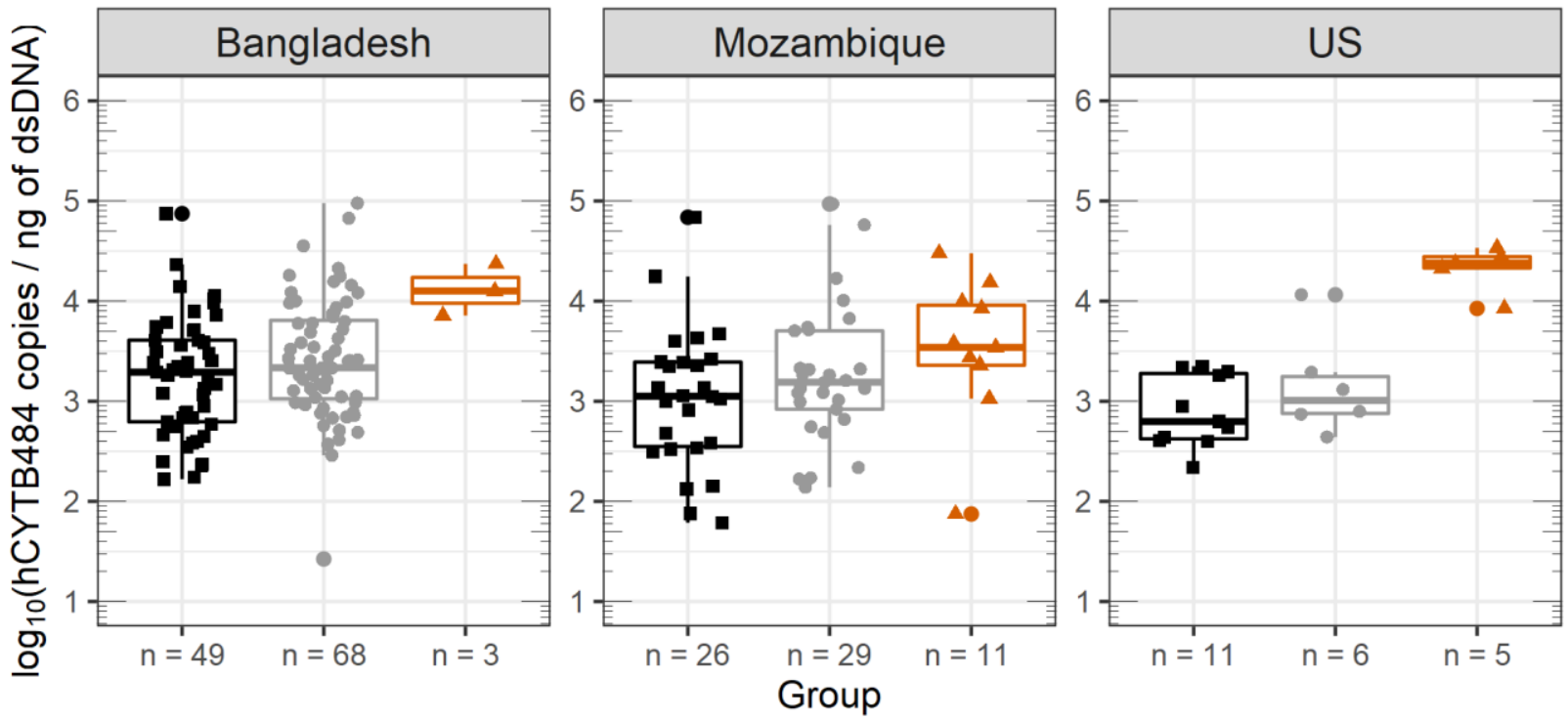

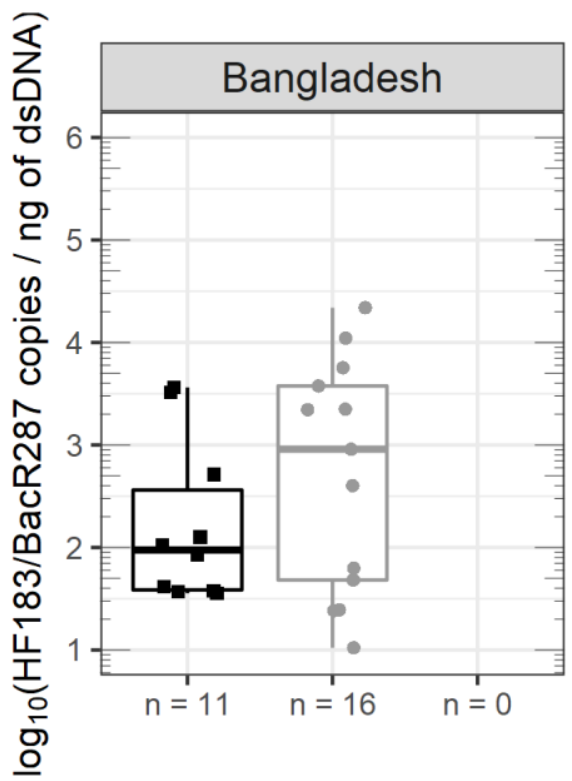

Enteric pathogens not detected \& asymptomatic

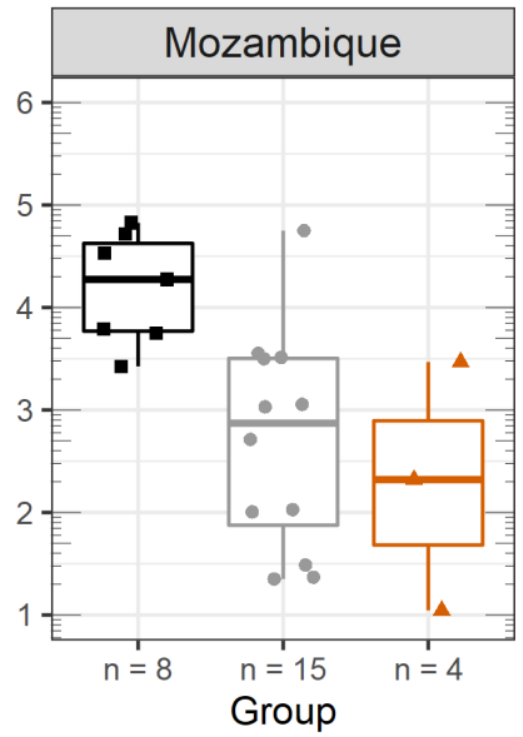

Norovirus detected \& asymptomatic

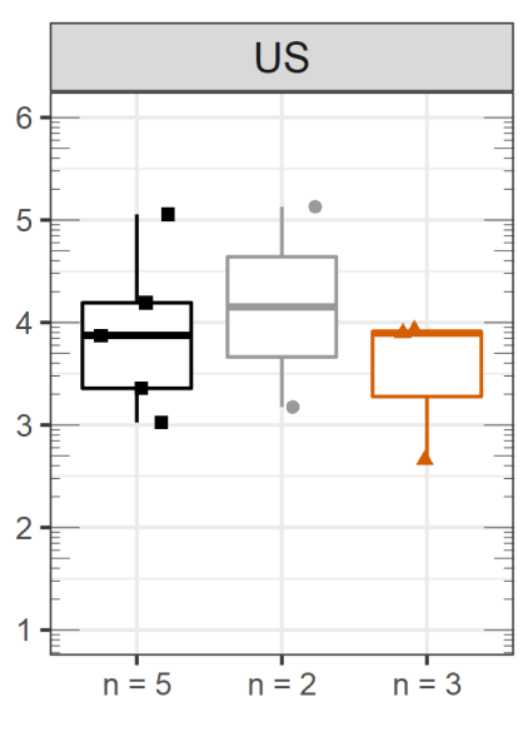

Norovirus detected \& symptomatic

Figure 1. Box and whisker plots of hCYTB484 (top plot) and HF183/BacR287 (bottom plot) concentrations for the various health statuses in this study. Horizontal lines (box) denote the $25^{\text {th }}$, $50^{\text {th }}$, and $7^{\text {th }}$ percentiles and the end of the vertical lines (whiskers) denote the maximum or minimum value of the data that is within 1.5 times the interquartile range over the $75^{\text {th }}$ percentile or under the $25^{\text {th }}$ percentile. All concentrations are plotted as $\log _{10}($ concentration +1$)$ and concentrations from feces are normalized to concentration of dsDNA (ng of dsDNA determined by Qubit). The number of quantifiable samples is shown at x-axis tick mark of each box and whisker (" $n=\# ")$. HF183/BacR287 plots have different numbers of quantifiable samples because HF183/BacR287 was detected in only $53 \%$ and quantifiable in $37 \%$ of all samples. 


\section{References}

(1) Boehm, A. B.; Van De Werfhorst, L. C.; Griffith, J. F.; Holden, P. A.; Jay, J. A.; Shanks, O. C.; Wang, D.; Weisberg, S. B. Performance of Forty-One Microbial Source Tracking Methods: A Twenty-Seven Lab Evaluation Study. Water Res. 2013, 47 (18), 6812-6828. https://doi.org/10.1016/j.watres.2012.12.046.

(2) Harris, A. R.; Pickering, A. J.; Harris, M.; Doza, S.; Islam, M. S.; Unicomb, L.; Luby, S.; Davis, J.; Boehm, A. B. Ruminants Contribute Fecal Contamination to the Urban Household Environment in Dhaka, Bangladesh. Environ. Sci. Technol. 2016, 50 (9), 4642-4649. https://doi.org/10.1021/acs.est.5b06282.

(3) Nshimyimana, J. P.; Cruz, M. C.; Thompson, R. J.; Wuertz, S. Bacteroidales Markers for Microbial Source Tracking in Southeast Asia. Water Res. 2017, 118, 239-248. https://doi.org/10.1016/j.watres.2017.04.027.

(4) Odagiri, M.; Schriewer, A.; Hanley, K.; Wuertz, S.; Misra, P. R.; Panigrahi, P.; Jenkins, M. W. Validation of Bacteroidales Quantitative PCR Assays Targeting Human and Animal Fecal Contamination in the Public and Domestic Domains in India. Sci. Total Environ. 2015, 502, 462-470. https://doi.org/10.1016/j.scitotenv.2014.09.040.

(5) Reischer, G. H.; Ebdon, J. E.; Bauer, J. M.; Schuster, N.; Ahmed, W.; Åström, J.; Blanch, A. R.; Blöschl, G.; Byamukama, D.; Coakley, T.; Ferguson, C.; Goshu, G.; Ko, G.; de Roda Husman, A. M.; Mushi, D.; Poma, R.; Pradhan, B.; Rajal, V.; Schade, M. A.; Sommer, R.; Taylor, H.; Toth, E. M.; Vrajmasu, V.; Wuertz, S.; Mach, R. L.; Farnleitner, A. H. Performance Characteristics of QPCR Assays Targeting Human- and RuminantAssociated Bacteroidetes for Microbial Source Tracking across Sixteen Countries on Six Continents. Environ. Sci. Technol. 2013, 47 (15), 8548-8556. https://doi.org/10.1021/es304367t.

(6) Caldwell, J. M.; Raley, M. E.; Levine, J. F. Mitochondrial Multiplex Real-Time PCR as a Source Tracking Method in Fecal-Contaminated Effluents. Environ. Sci. Technol. 2007, 41 (9), 3277-3283. https://doi.org/10.1021/es062912s.

(7) Schill, W. B.; Mathes, M. V. Real-Time PCR Detection and Quantification of Nine Potential Sources of Fecal Contamination by Analysis of Mitochondrial Cytochrome b Targets. Environ. Sci. Technol. 2008, 42 (14), 5229-5234. https://doi.org/10.1021/es800051z.

(8) He, X.; Liu, P.; Zheng, G.; Chen, H.; Shi, W.; Cui, Y.; Ren, H.; Zhang, X.-X. Evaluation of Five Microbial and Four Mitochondrial DNA Markers for Tracking Human and Pig Fecal Pollution in Freshwater. Sci. Rep. 2016, 6 (1), 35311. https://doi.org/10.1038/srep35311.

(9) Zhu, K.; Suttner, B.; Pickering, A.; Konstantinidis, K. T.; Brown, J. A Novel Droplet Digital PCR Human MtDNA Assay for Fecal Source Tracking. Water Res. 2020, 183, 116085. https://doi.org/10.1016/j.watres.2020.116085. 
(10) Microbial Source Tracking: Methods, Applications, and Case Studies; Hagedorn, C., Blanch, A. R., Harwood, V. J., Eds.; Springer New York: New York, NY, 2011. https://doi.org/10.1007/978-1-4419-9386-1.

(11) Martellini, A.; Payment, P.; Villemur, R. Use of Eukaryotic Mitochondrial DNA to Differentiate Human, Bovine, Porcine and Ovine Sources in Fecally Contaminated Surface Water. Water Res. 2005, 39 (4), 541-548. https://doi.org/10.1016/j.watres.2004.11.012.

(12) Peña-Gonzalez, A.; Soto-Girón, M. J.; Smith, S.; Sistrunk, J.; Montero, L.; Páez, M.; Ortega, E.; Hatt, J. K.; Cevallos, W.; Trueba, G.; Levy, K.; Konstantinidis, K. T. Metagenomic Signatures of Gut Infections Caused by Different Escherichia Coli Pathotypes. Appl. Environ. Microbiol. 2019, 85 (24), 1-18. https://doi.org/10.1128/AEM.01820-19.

(13) Boyapati, R. K.; Dorward, D. A.; Tamborska, A.; Kalla, R.; Ventham, N. T.; Doherty, M. K.; Whitfield, P. D.; Gray, M.; Loane, J.; Rossi, A. G.; Satsangi, J.; Ho, G. Mitochondrial DNA Is a Pro-Inflammatory Damage-Associated Molecular Pattern Released During Active IBD. Inflamm. Bowel Dis. 2018, 24 (10), 2113-2122. https://doi.org/10.1093/ibd/izy095.

(14) Leon, J. S.; Kingsley, D. H.; Montes, J. S.; Richards, G. P.; Lyon, G. M.; Abdulhafid, G. M.; Seitz, S. R.; Fernandez, M. L.; Teunis, P. F.; Flick, G. J.; Moe, C. L. Randomized, Double-Blinded Clinical Trial for Human Norovirus Inactivation in Oysters by High Hydrostatic Pressure Processing. Appl. Environ. Microbiol. 2011, 77 (15), 5476-5482. https://doi.org/10.1128/AEM.02801-10.

(15) Knee, J.; Sumner, T.; Adriano, Z.; Berendes, D.; de Bruijn, E.; Schmidt, W. P.; Nalá, R.; Cumming, O.; Brown, J. Risk Factors for Childhood Enteric Infection in Urban Maputo, Mozambique: A Cross-Sectional Study. PLoS Negl. Trop. Dis. 2018, 12 (11), 1-19. https://doi.org/10.1371/journal.pntd.0006956.

(16) Brown, J.; Cumming, O.; Bartram, J.; Cairncross, S.; Ensink, J.; Holcomb, D.; Knee, J.; Kolsky, P.; Liang, K.; Liang, S.; Nala, R.; Norman, G.; Rheingans, R.; Stewart, J.; Zavale, O.; Zuin, V.; Schmidt, W.-P. A Controlled, before-and-after Trial of an Urban Sanitation Intervention to Reduce Enteric Infections in Children: Research Protocol for the Maputo Sanitation (MapSan) Study, Mozambique. BMJ Open 2015, 5 (6), e008215-e008215. https://doi.org/10.1136/bmjopen-2015-008215.

(17) Pickering, A. J.; Crider, Y.; Sultana, S.; Swarthout, J.; Goddard, F. G.; Anjerul Islam, S.; Sen, S.; Ayyagari, R.; Luby, S. P. Effect of In-Line Drinking Water Chlorination at the Point of Collection on Child Diarrhoea in Urban Bangladesh: A Double-Blind, ClusterRandomised Controlled Trial. Lancet Glob. Heal. 2019, 7 (9), e1247-e1256. https://doi.org/10.1016/S2214-109X(19)30315-8.

(18) Berendes, D.; Capone, D.; Knee, J.; Holcomb, D.; Sultana, S.; Pickering, A. J.; Brown, J. Associations between Enteric Pathogen Carriage and Height-for-Age, Weight-for-Age and Weight-for-Height in Children under 5 Years Old in Urban Dhaka, Bangladesh. 
Epidemiol. Infect. 2020, 148, e39. https://doi.org/10.1017/S0950268820000369.

(19) Navidad, J. F.; Griswold, D. J.; Gradus, M. S.; Bhattacharyya, S. Evaluation of Luminex XTAG Gastrointestinal Pathogen Analyte-Specific Reagents for High-Throughput, Simultaneous Detection of Bacteria, Viruses, and Parasites of Clinical and Public Health Importance. J. Clin. Microbiol. 2013, 51 (9), 3018-3024. https://doi.org/10.1128/JCM.00896-13.

(20) Green, H. C.; Haugland, R. A.; Varma, M.; Millen, H. T.; Borchardt, M. A.; Field, K. G.; Walters, W. A.; Knight, R.; Sivaganesan, M.; Kelty, C. A.; Shanks, O. C. Improved HF183 Quantitative Real-Time PCR Assay for Characterization of Human Fecal Pollution in Ambient Surface Water Samples. Appl. Environ. Microbiol. 2014, 80 (10), 3086-3094. https://doi.org/10.1128/AEM.04137-13.

(21) Kelty, C. A.; Varma, M.; Sivaganesan, M.; Haugland, R. A.; Shanks, O. C. Distribution of Genetic Marker Concentrations for Fecal Indicator Bacteria in Sewage and Animal Feces. Appl. Environ. Microbiol. 2012, 78 (12), 4225-4232. https://doi.org/10.1128/AEM.0781911.

(22) Whale, A. S.; De Spiegelaere, W.; Trypsteen, W.; Nour, A. A.; Bae, Y.-K.; Benes, V.; Burke, D.; Cleveland, M.; Corbisier, P.; Devonshire, A. S.; Dong, L.; Drandi, D.; Foy, C. A.; Garson, J. A.; He, H.-J.; Hellemans, J.; Kubista, M.; Lievens, A.; Makrigiorgos, M. G.; Milavec, M.; Mueller, R. D.; Nolan, T.; O’Sullivan, D. M.; Pfaffl, M. W.; Rödiger, S.; Romsos, E. L.; Shipley, G. L.; Taly, V.; Untergasser, A.; Wittwer, C. T.; Bustin, S. A.; Vandesompele, J.; Huggett, J. F. The Digital MIQE Guidelines Update: Minimum Information for Publication of Quantitative Digital PCR Experiments for 2020. Clin. Chem. 2020, 66 (8), 1012-1029. https://doi.org/10.1093/clinchem/hvaa125.

(23) Pentinmikko, N.; Katajisto, P. The Role of Stem Cell Niche in Intestinal Aging. Mech. Ageing Dev. 2020, 191, 111330. https://doi.org/10.1016/j.mad.2020.111330.

(24) Liu, T. C.; Vanbuskirk, K.; Ali, S. A.; Kelly, M. P.; Holtz, L. R.; Yilmaz, O. H.; Sadiq, K.; Iqbal, N.; Amadi, B.; Syed, S.; Ahmed, T.; Moore, S.; Ndao, I. M.; Isaacs, M. H.; Pfeifer, J. D.; Atlas, H.; Tarr, P. I.; Denno, D. M.; Moskaluk, C. A. A Novel Histological Index for Evaluation of Environmental Enteric Dysfunction Identifies GeographicSpecific Features of Enteropathy among Children with Suboptimal Growth. PLoS Negl. Trop. Dis. 2020, 14 (1), 1-21. https://doi.org/10.1371/journal.pntd.0007975.

(25) Brown, J.; Cumming, O. Stool-Based Pathogen Detection Offers Advantages as an Outcome Measure for Water, Sanitation, and Hygiene Trials. Am. J. Trop. Med. Hyg. 2020, 102 (2), 260-261. https://doi.org/10.4269/ajtmh.19-0639.

(26) Baqui, A. H.; Black, R. E.; Yunus, M.; Hoque, A. R. A.; Chowdhury, H. R.; Sack, R. B. Methodological Issues in Diarrhoeal Diseases Epidemiology: Definition of Diarrhoeal Episodes. Int. J. Epidemiol. 1991, 20 (4), 1057-1063. https://doi.org/10.1093/ije/20.4.1057.

(27) Arnold, B. F.; Galiani, S.; Ram, P. K.; Hubbard, A. E.; Briceño, B.; Gertler, P. J.; Colford, 
J. M. Optimal Recall Period for Caregiver-Reported Illness in Risk Factor and Intervention Studies: A Multicountry Study. Am. J. Epidemiol. 2013, 177 (4), 361-370. https://doi.org/10.1093/aje/kws281.

(28) Mayer, R. E.; Reischer, G. H.; Ixenmaier, S. K.; Derx, J.; Blaschke, A. P.; Ebdon, J. E.; Linke, R.; Egle, L.; Ahmed, W.; Blanch, A. R.; Byamukama, D.; Savill, M.; Mushi, D.; Cristóbal, H. A.; Edge, T. A.; Schade, M. A.; Aslan, A.; Brooks, Y. M.; Sommer, R.; Masago, Y.; Sato, M. I.; Taylor, H. D.; Rose, J. B.; Wuertz, S.; Shanks, O. C.; Piringer, H.; Mach, R. L.; Savio, D.; Zessner, M.; Farnleitner, A. H. Global Distribution of HumanAssociated Fecal Genetic Markers in Reference Samples from Six Continents. Environ. Sci. Technol. 2018, 52 (9), 5076-5084. https://doi.org/10.1021/acs.est.7b04438.

(29) Williams, J. M.; Duckworth, C. A.; Burkitt, M. D.; Watson, A. J. M. M.; Campbell, B. J.; Pritchard, D. M. Epithelial Cell Shedding and Barrier Function: A Matter of Life and Death at the Small Intestinal Villus Tip. Vet. Pathol. 2015, 52 (3), 445-455. https://doi.org/10.1177/0300985814559404.

(30) Hall, P. A.; Coates, P. J.; Ansari, B.; Hopwood, D. Regulation of Cell Number in the Mammalian Gastrointestinal Tract: The Importance of Apoptosis. J. Cell Sci. 1994, 107 ( Pt 1 (12), 3569-3577.

(31) Barkla, D. H.; Gibson, P. R. The Fate of Epithelial Cells in the Human Large Intestine. Pathology 1999, 31 (3), 230-238. https://doi.org/10.1080/003130299105043.

(32) Watson, A. J. M.; Hall, L. J.; Hughes, K. R. Cell Shedding: Old Questions Answered. Gastroenterology 2012, 143 (5), 1389-1391. https://doi.org/10.1053/j.gastro.2012.09.025.

(33) Eisenhoffer, G. T.; Loftus, P. D.; Yoshigi, M.; Otsuna, H.; Chien, C.-B.; Morcos, P. A.; Rosenblatt, J. Crowding Induces Live Cell Extrusion to Maintain Homeostatic Cell Numbers in Epithelia. Nature 2012, 484 (7395), 546-549. https://doi.org/10.1038/nature10999.

(34) Bullen, T. F.; Forrest, S.; Campbell, F.; Dodson, A. R.; Hershman, M. J.; Pritchard, D. M.; Turner, J. R.; Montrose, M. H.; Watson, A. J. M. Characterization of Epithelial Cell Shedding from Human Small Intestine. Lab. Investig. 2006, 86 (10), 1052-1063. https://doi.org/10.1038/labinvest.3700464.

(35) Patterson, A. M.; Watson, A. J. M. Deciphering the Complex Signaling Systems That Regulate Intestinal Epithelial Cell Death Processes and Shedding. Front. Immunol. 2017, 8 (JUL), 1-7. https://doi.org/10.3389/fimmu.2017.00841.

(36) Williams, J. M.; Duckworth, C. A.; Watson, A. J. M.; Frey, M. R.; Miguel, J. C.; Burkitt, M. D.; Sutton, R.; Hughes, K. R.; Hall, L. J.; Caamano, J. H.; Campbell, B. J.; Pritchard, D. M. A Mouse Model of Pathological Small Intestinal Epithelial Cell Apoptosis and Shedding Induced by Systemic Administration of Lipopolysaccharide. Dis. Model. Mech. 2013, 6 (6), 1388-1399. https://doi.org/10.1242/dmm.013284.

(37) Knodler, L. A.; Vallance, B. A.; Celli, J.; Winfree, S.; Hansen, B.; Montero, M.; Steele- 
Mortimer, O. Dissemination of Invasive Salmonella via Bacterial-Induced Extrusion of Mucosal Epithelia. Proc. Natl. Acad. Sci. 2010, 107 (41), 17733-17738. https://doi.org/10.1073/pnas.1006098107.

(38) Boshuizen, J. A.; Reimerink, J. H. J.; Korteland-van Male, A. M.; van Ham, V. J. J.; Koopmans, M. P. G.; Büller, H. A.; Dekker, J.; Einerhand, A. W. C. Changes in Small Intestinal Homeostasis, Morphology, and Gene Expression during Rotavirus Infection of InfantMice. J. Virol. 2003, 77 (24), 13005-13016. https://doi.org/10.1128/JVI.77.24.13005-13016.2003.

(39) Ahlquist, D. A.; Harrington, J. J.; Burgart, L. J.; Roche, P. C. Morphometric Analysis of the "Mucocellular Layer" Overlying Colorectal Cancer and Normal Mucosa: Relevance to Exfoliation and Stool Screening. Hum. Pathol. 2000, 31 (1), 51-57. https://doi.org/10.1016/S0046-8177(00)80198-7.

(40) Atmar, R. L.; Ramani, S.; Estes, M. K. Human Noroviruses. Curr. Opin. Infect. Dis. 2018, 31 (5), 422-432. https://doi.org/10.1097/QCO.0000000000000476.

(41) Estes, M. K.; Ettayebi, K.; Tenge, V. R.; Murakami, K.; Karandikar, U.; Lin, S. C.; Ayyar, B. V.; Cortes-Penfield, N. W.; Haga, K.; Neill, F. H.; Opekun, A. R.; Broughman, J. R.; Zeng, X. L.; Blutt, S. E.; Crawford, S. E.; Ramani, S.; Graham, D. Y.; Atmar, R. L. Human Norovirus Cultivation in Nontransformed Stem Cell-Derived Human Intestinal Enteroid Cultures: Success and Challenges. Viruses 2019, 11 (7), 9-11. https://doi.org/10.3390/v11070638.

(42) Karst, S. M.; Tibbetts, S. A. Recent Advances in Understanding Norovirus Pathogenesis. J. Med. Virol. 2016, 88 (11), 1837-1843. https://doi.org/10.1002/jmv.24559.

(43) Guerrant, R. L.; Araujo, V.; Soares, E.; Kotloff, K.; Lima, A. A. M.; Cooper, W. H.; Lee, A. G. Measurement of Fecal Lactoferrin as a Marker of Fecal Leukocytes. J. Clin. Microbiol. 1992, 30 (5), 1238-1242. https://doi.org/10.1128/JCM.30.5.1238-1242.1992.

(44) Mercado, E. H.; Ochoa, T. J.; Ecker, L.; Cabello, M.; Durand, D.; Barletta, F.; Molina, M.; Gil, A. I.; Huicho, L.; Lanata, C. F.; Cleary, T. G. Fecal Leukocytes in Children Infected with Diarrheagenic Escherichia Coli. J. Clin. Microbiol. 2011, 49 (4), 13761381. https://doi.org/10.1128/JCM.02199-10.

(45) Luissint, A. C.; Parkos, C. A.; Nusrat, A. Inflammation and the Intestinal Barrier: Leukocyte-Epithelial Cell Interactions, Cell Junction Remodeling, and Mucosal Repair. Gastroenterology 2016, 151 (4), 616-632. https://doi.org/10.1053/j.gastro.2016.07.008.

(46) Ingelsson, B.; Söderberg, D.; Strid, T.; Söderberg, A.; Bergh, A.-C.; Loitto, V.; Lotfi, K.; Segelmark, M.; Spyrou, G.; Rosén, A. Lymphocytes Eject Interferogenic Mitochondrial DNA Webs in Response to CpG and Non-CpG Oligodeoxynucleotides of Class C. Proc. Natl. Acad. Sci. 2018, 115 (3), E478-E487. https://doi.org/10.1073/pnas.1711950115.

(47) Boyapati, R. K.; Tamborska, A.; Dorward, D. A.; Ho, G.-T. Advances in the Understanding of Mitochondrial DNA as a Pathogenic Factor in Inflammatory Diseases. 
F1000Research 2017, 6 (0), 169. https://doi.org/10.12688/f1000research.10397.1.

(48) Colford, J. M.; Wade, T. J.; Schiff, K. C.; Wright, C. C.; Griffith, J. F.; Sandhu, S. K.; Burns, S.; Sobsey, M.; Lovelace, G.; Weisberg, S. B. Water Quality Indicators and the Risk of Illness at Beaches With Nonpoint Sources of Fecal Contamination. Epidemiology 2007, 18 (1), 27-35. https://doi.org/10.1097/01.ede.0000249425.32990.b9.

(49) Dwight, R. H.; Baker, D. B.; Semenza, J. C.; Olson, B. H. Health Effects Associated with Recreational Coastal Water Use: Urban Versus Rural California. Am. J. Public Health 2004, 94 (4), 565-567. https://doi.org/10.2105/AJPH.94.4.565.

(50) Wade, T. J.; Calderon, R. L.; Sams, E.; Beach, M.; Brenner, K. P.; Williams, A. H.; Dufour, A. P. Rapidly Measured Indicators of Recreational Water Quality Are Predictive of Swimming-Associated Gastrointestinal Illness. Environ. Health Perspect. 2006, 114 (1), 24-28. https://doi.org/10.1289/ehp.8273.

(51) Wade, T. J.; Calderon, R. L.; Brenner, K. P.; Sams, E.; Beach, M.; Haugland, R.; Wymer, L.; Dufour, A. P. High Sensitivity of Children to Swimming-Associated Gastrointestinal Illness. Epidemiology 2008, 19 (3), 375-383. https://doi.org/10.1097/EDE.0b013e318169cc87.

(52) Yau, V. M.; Schiff, K. C.; Arnold, B. F.; Griffith, J. F.; Gruber, J. S.; Wright, C. C.; Wade, T. J.; Burns, S.; Hayes, J. M.; McGee, C.; Gold, M.; Cao, Y.; Boehm, A. B.; Weisberg, S. B.; Colford, J. M. Effect of Submarine Groundwater Discharge on Bacterial Indicators and Swimmer Health at Avalon Beach, CA, USA. Water Res. 2014, 59, 23-36. https://doi.org/10.1016/j.watres.2014.03.050.

(53) Sukhrie, F. H. A.; Teunis, P.; Vennema, H.; Copra, C.; Thijs Beersma, M. F. C.; Bogerman, J.; Koopmans, M. Nosocomial Transmission of Norovirus Is Mainly Caused by Symptomatic Cases. Clin. Infect. Dis. 2012, 54 (7), 931-937. https://doi.org/10.1093/cid/cir971.

(54) He, X.; Chen, H.; Shi, W.; Cui, Y.; Zhang, X.-X. Persistence of Mitochondrial DNA Markers as Fecal Indicators in Water Environments. Sci. Total Environ. 2015, 533, 383390. https://doi.org/10.1016/j.scitotenv.2015.06.119.

(55) Korajkic, A.; McMinn, B.; Harwood, V. Relationships between Microbial Indicators and Pathogens in Recreational Water Settings. Int. J. Environ. Res. Public Health 2018, 15 (12), 2842. https://doi.org/10.3390/ijerph15122842. 
medRxiv preprint doi: https://doi.org/10.1101/2022.02.24.22271477; this version posted February 25, 2022. The copyright holder for this preprint (which was not certified by peer review) is the author/funder, who has granted medRxiv a license to display the preprint in perpetuity.

All rights reserved. No reuse allowed without permission.

\section{For Table of Contents Only}

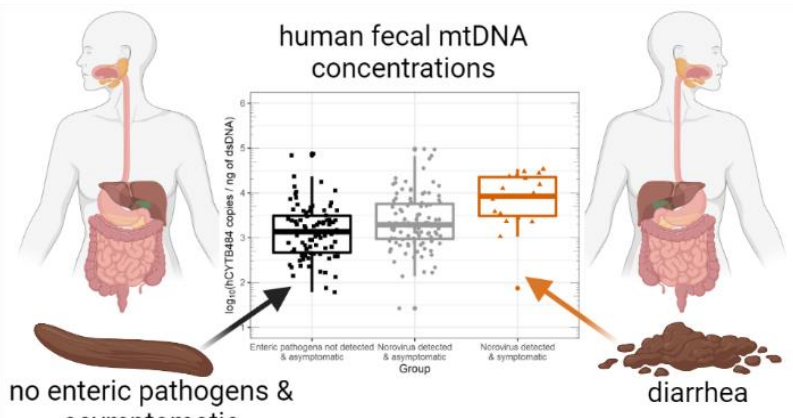
asymptomatic 